\title{
Properties of Dried Apricots Pretreated by Ultrasound-Assisted Osmotic Dehydration and Application of Active Coatings
}

\author{
Roghieh Sakooei-Vayghan ${ }^{\top}$, \\ Seyed Hadi \\ Peighambardoust ${ }^{1 *} \odot$, \\ Javad Hesari`®, Maral \\ Soltanzadeh ${ }^{\top}$ and Donatella \\ Peressini²。
}

'Department of Food Science, College of Agriculture, University of Tabriz, 29th Bahman Blvd., 5166616471 Tabriz, Iran

2Department of Agricultural, Food, Environmental and Animal Sciences, University of Udine, via Sondrio 2/A, 33100 Udine, Italy

Received: 4 August 2019 Accepted: 31 July 2020

\section{(i)}

*Corresponding author:

Phone: +984133392052

Fax: +984133345332

E-mail: peighambardoust@tabrizu.ac.ir

\section{SUMMARY}

Research background. The worldwide demand for healthy and sulphur-free dried vegetables and fruits has grown. Combined ultrasound-assisted osmotic dehydration (UOD) and application of active coatings incorporating natural preservatives represents an attractive alternative to sulphuring to preserve the sensorial and nutritional quality of dried fruits. The aim of this study is to investigate the effect of osmotic dehydration (OD) and UOD, and the use of pectin coatings (alone or with citric acid or ascorbic acid) on physical, textural and microstructural properties of hot air-dried apricots.

Experimental approach. Fresh apricot cubes $\left(1 \mathrm{~cm}^{3}\right)$ were pretreated with either OD at $55^{\circ} \mathrm{C}$ for 30 and $45 \mathrm{~min}$ or $\mathrm{UOD}$ at two ultrasonic frequencies of 25 and $35 \mathrm{kHz}$ for 30 and $45 \mathrm{~min}$ followed by application of active coatings with pectin alone, pectin with citric acid or pectin with ascorbic acid for $10 \mathrm{~min}$. All pretreated coated samples were then hot air-dried at $60^{\circ} \mathrm{C}$ until a final moisture content of $20 \%$ (wet basis) was reached. Physical (shrinkage, apparent and bulk densities), chemical (browning value and water activity) and textural properties (firmness and shrinkage), microstructure and microbial load of dried apricots were studied.

Results and conclusions. Application of OD and UOD improved physical and textural properties of the dried apricots. Moreover, apparent and bulk densities, rehydration capacity of OD and UOD pretreated samples increased, while shrinkage, water activity and microbial load decreased. Firmness of UOD pretreated samples was significantly $(p<0.05)$ lower than that of OD ones. Likewise, increasing ultrasound frequency from 25 to $35 \mathrm{kHz}$ led to a significant decrease in $F_{\text {max }}$ values of dried apricots. Furthermore, coating of the processed samples with pectin and citric acid increased $F_{\max }$ value and decreased rehydration capacity of dried apricots. Scanning electron microscopy of both OD and UOD samples illustrated improvement of structural properties. The utilization of both OD pretreatment and edible pectin coatings resulted in a decrease in browning values. However, UOD increased browning values of the dried apricots. Coating of UOD samples with pectin and ascorbic acid resulted in substantial discolouration in hot air-dried apricots.

Novelty and scientific contribution. This study advances the knowledge in the field of fruit drying by combined application of OD or UOD pretreatments with active edible coatings on different properties of hot air-dried apricots.

Key words: apricot, hot air drying, osmotic dehydration, ultrasound-assisted osmotic dehydration, active coating, physical properties

\section{INTRODUCTION}

Nowadays, there is a growing demand for healthy and nutritive foods. Apricot contains a high content of polyphenolic compounds, carotenoids, minerals and vitamins, which are nutritionally valuable compounds (1). Nutritional content in fruits and vegetables such as apricot not only depends on size, variety and ripeness (2), but also on processing conditions (3). The small amounts of apricot are consumed fresh, and its processing is necessary to extend its shelf life. Hot air drying is most common process to increase the shelf life of fruits, but it causes irreversible changes in nutritional and physical properties of 
apricots such as colour and textural variations and decreases nutritional value (3). Textural damages created in air-dried fruits and vegetables include extreme shrinkage, low rehydration capacity and texture firmness. Colour changes in hot air-dried apricot derive from ascorbic acid oxidation, enzymatic and non-enzymatic browning reactions. Sulphur dioxide is normally used as a synthetic antioxidant before drying to preserve the colour and to protect carotenoids, polyphenolic compounds and vitamin $C(4,5)$. However, its use in fresh fruits and vegetables is restricted by Food and Drug Administration (FDA) regulations because of its role in the initiation of asthmatic reactions in sensitive people.

Osmotic dehydration (OD) pretreatment can substitute sulphite application before drying. This process improves nutritional value, texture properties, reduces shrinkage, and prevents colour deterioration during the drying of fruits and vegetables (6). Concerning low mass transfer rate in the $O D$, the use of high-power ultrasound can enhance mass transfer rate of the process (7). Combining power ultrasound in OD processing creates cavities in the liquid phase and enhances the rate of mass transfer by forming micro agitation and reducing the thickness of the solid diffusion boundary layer. In the solid phase, alternating compressions and expansions result in a sponge-like effect and create microchannels that facilitate the flow of water out of the solid medium (8).

Coating of fruits and vegetables with edible carbohydrate-based coatings before drying is another pretreatment that can decrease oxidation and nutritional compound loss during hot air drying. Furthermore, coatings can minimize colour changes in the dried materials due to gas barrier properties (9). Garcia et al. (10) reported that the application of edible coatings on papaya before drying increased the retention of vitamin C content compared with non-coated dried papaya. Moreover, Silva et al. (9) found that coating of pineapple samples with pectin, and whey protein isolate and locust bean gum coatings decrease the loss of vitamin $C$ content in coated samples during drying. They showed that the lowest colour change among samples happened in the pectin-coated ones. Ghasemzadeh et al. (11) found that the use of pectin coating on raisin before drying resulted in better colour, flavour and texture.

There are many published papers about the use of ultrasound-assisted osmotic dehydration (UOD) and its effect on quality parameters of fruits and vegetables. To the best of our knowledge, no study has been done combining UOD and the application of active edible coatings. Thus, the novelty of the paper is the combined application of UOD and active edible coatings with different antioxidant agents before hot air drying. We investigated the effect of such processes on physical (shrinkage, apparent and bulk densities), chemical (browning value and water activity) and textural properties (maximum force and shrinkage), microstructure and microbial properties of dried apricots.

\section{MATERIALS AND METHODS}

\section{Chemicals}

Liquid sorbitol ( $70^{\circ}$ Brix) (Foodchem, Shanghai, PR China) was used as osmotic solution. Low methylated amidated pec-

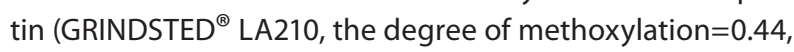
degree of amidation=0.18; DANISCO, Copenhagen, Denmark), ascorbic acid (Northeast Pharmaceutical, Shenyang, PR China) and citric acid (Union Biochemical Co., Yixing, PR China) were used for the preparation of polysaccharide-based active edible coatings. Glycerol (Sigma-Aldrich, Merck, Munich, Germany) served as plasticizer agent.

\section{Fruit sample preparation}

Fresh apricots (Prunus armeniaca) cultivar Harostar (formerly HW 436) from Asgarabad, Iran, were directly taken from the Urmia (Iran) agricultural region and transported to the laboratory in wooden boxes. Mature fruits with average mass of $25 \mathrm{~g}$ and average diameter of $3 \mathrm{~cm}$ were selected. The apricots were refrigerated at $4{ }^{\circ} \mathrm{C}$ and $80-90 \%$ relative humidity for maximum seven days until they were used. The initial moisture content of the fruits was $80 \%$ (wet basis). Before each experiment, apricots were removed from the refrigerator and left to equilibrate to room temperature. They were then washed, halved, stoned and cut to $1 \mathrm{~cm}^{3}$ cubes with a household tool.

\section{Osmotic dehydration}

The sliced cubes $\left(1 \mathrm{~cm}^{3}\right)$ of fresh apricots $(100 \mathrm{~g})$ were immersed in sorbitol solution ( $35^{\circ} \mathrm{Brix}, 400 \mathrm{~g}$ ) giving a mass ratio of fruit to osmotic solution 1:4. Osmotic dehydration (OD) was carried out at $55^{\circ} \mathrm{C}$ for 30 and $45 \mathrm{~min}$. To maintain this temperature constant, the glass beaker containing apricot cubes immersed in the osmotic solution was placed in a water bath kept at $55^{\circ} \mathrm{C}$. The process temperature was controlled by a thermometer during osmosis. Using high OD temperature ensured the inactivation of polyphenol oxidase enzyme, as confirmed by Cheng et al. (12). Short treatment times below $45 \mathrm{~min}$ also limit the solute uptake by fruit samples due to the fact that water loss to solid gain ratio stays high at the early stages of the process $(13,14)$. OD-treated apricot cubes were removed from the sorbitol solution and their excess liquid was taken using an absorbent paper.

\section{Ultrasound-assisted osmotic dehydration}

Fresh apricot cubes prepared under the conditions mentioned above for OD treatment were subjected to power ultrasound (HD 2070.2; Sonopuls Berlin, Germany) with an ultrasound intensity of $4.3 \mathrm{~W} / \mathrm{g}$. The probe was put in the centre of a glass beaker containing sorbitol solution and apricot cubes at the height of $25 \mathrm{~mm}$ from the base of the container. Two levels of 25 and $35 \mathrm{kHz}$ ultrasonic frequencies were applied for 30 and $45 \mathrm{~min}$. To avoid temperature fluctuation during ultrasound processing, ice packs were placed around the glass beaker 
containing samples and the process temperature was controlled by a thermometer. Osmotic solution was stirred every 2 min by a glass agitator to ensure a homogenous osmotic treatment. The fruits were removed from the sorbitol solution, and the excess osmotic solution was removed through an absorbent paper.

\section{Active coating application}

Following OD or UOD treatments, apricot samples were coated using a solution of low methylated amidated pectin ( $2 \%$ ) prepared according to the method explained by Garcia et al. (10). For this purpose, $0.2 \mathrm{~g}$ glycerol (as plasticizer) and 2 $\mathrm{g}$ citric or ascorbic acid (as antioxidants) were added to every $100 \mathrm{~mL}$ of pectin solution. Apricot cubes were dipped in pectin, pectin with citric acid or pectin with ascorbic acid solutions for $10 \mathrm{~min}$, followed by rinsing and removing their excess coating liquid, and hot-air drying.

\section{Convective hot air drying}

Apricot cubes were dried using a laboratory convective tray dryer (Armfield Ltd., Ringwood, Hampshire, UK) with a total capacity of approx. $3 \mathrm{~kg}$ using four sample trays, which were suspended from a digital balance mounted on the dryer top. The dryer was previously heated to the set-point tem-

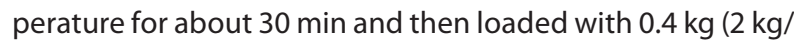
$\mathrm{m}^{2}$ ) pretreated and coated apricot cubes. Samples were dried at $60{ }^{\circ} \mathrm{C}$ with an air velocity of $1.5 \mathrm{~m} / \mathrm{s}$. Changes of the sample mass during drying were continuously recorded until a final moisture content of 19-20\% (wet basis) was reached (15).

\section{Moisture content measurement}

The moisture content was estimated by vacuum drying (vacuum oven Vacutherm VT6025; Thermo Fisher Scientific Inc., Branchburg, NJ, USA) at $60^{\circ} \mathrm{C}$ until a constant mass was reached (16).

\section{Soluble solids measurement}

The total soluble solids of the liquid phase of the fruit $\left(X_{s^{\prime}}\right.$ in $\mathrm{g}$ soluble solids per $\mathrm{g}$ fruit liquid phase) were estimated by a refractometer (ATAGO, Pal ALFA, Tokyo, Japan). For fresh apricot, the liquid phase was obtained directly by pressing the fruit. In the case of the dried fruit, a controlled mass of distilled water (approx. $20 \mathrm{~g}$ ) was added to each sample and the mix was homogenized to obtain the liquid phase, which was directly measured in the refractometer. The soluble solid content of the dried fruit was obtained by using the following equations:

$$
\begin{gathered}
X_{\mathrm{s} \text { (total) }}=\frac{X_{\mathrm{s}}}{X_{\mathrm{s}}+X_{\mathrm{w}}} \\
X_{\mathrm{s}}=\left(m_{\mathrm{d}} \cdot X_{\mathrm{wd}}+m_{\mathrm{w}}\right) \cdot{ }^{\circ} \mathrm{Brix} /\left(100-{ }^{\circ} \mathrm{Brix}\right) \cdot m_{\mathrm{d}}
\end{gathered}
$$

where $X_{s(\text { total) }}$ is the mass fraction of total soluble solids (in $\mathrm{g}$ soluble solids per $\mathrm{g}$ fruit liquid phase), $X_{\mathrm{s}}$ is the mass fraction of soluble solids (in $g$ soluble solids per $g$ fruit), $X_{w}$ is a mass fraction of water, $m_{\mathrm{d}}$ and $m_{\mathrm{w}}$ are the mass of the dried fruit and the added water used in the analysis, respectively, and $X_{w d}$ is the mass fraction of water in the dried fruit.

\section{Measurement of water activity}

A hygrometer (0.003 accuracy; LabMaster, Novasina AG, Lachen, Switzerland) was applied to determine water activity of samples after calibration with $\mathrm{K}_{2} \mathrm{SO}_{4}$ standard solution $\left(a_{\mathrm{w}}=0.972\right)$.

\section{Determination of shrinkage, apparent and bulk densities}

Shrinkage $\left(S_{b}\right)$ of samples was estimated by measuring the volume of apricot samples before and after drying. For this purpose, five apricot cubes were selected randomly, and their volume was measured by toluene displacement method. Shrinkage and apparent density $\left(\rho_{\mathrm{a}}\right)$ of samples were calculated using the following equations, respectively:

$$
\begin{gathered}
S_{b}=\frac{V_{0}-V}{V_{0}} \cdot 100 \\
\rho_{a}=\frac{m}{V}
\end{gathered}
$$

where $S_{b}$ is shrinkage (\%), $V_{0}$ and $V$ are the initial and final volumes of apricot $\left(\mathrm{cm}^{3}\right)$, respectively, $\rho_{\mathrm{a}}$ is the apparent density $\left(\mathrm{g} / \mathrm{cm}^{3}\right)$, and $m$ is the apricot mass $(\mathrm{g})$.

Bulk density $\left(\rho_{\mathrm{b}}\right)$, which is a function of mass fraction of water in samples, was calculated with the following equation:

$$
\rho_{\mathrm{b}}=\frac{1}{\frac{X_{\mathrm{w}}}{1000}+\frac{1-X_{\mathrm{w}}}{1590}}
$$

where $\rho_{\mathrm{b}}\left(\mathrm{g} / \mathrm{cm}^{3}\right)$ is the bulk density and $X_{\mathrm{w}}$ is the mass fraction of water $(\mathrm{g} / \mathrm{g})$.

\section{Determination of rehydration capacity}

To measure rehydration capacity, dried samples were weighed and then placed in a glass beaker containing 150 $\mathrm{mL}$ distilled water at room temperature for $6 \mathrm{~h}$. Samples were then removed from the distilled water and placed on a paper tissue to eliminate residual water before weighing. Rehydration capacity was calculated as follows (17):

$$
\text { Rehydration capacity }=\frac{m}{m_{0}}
$$

where $m_{0}$ and $m$ are the initial and final mass of samples $(\mathrm{g})$, respectively.

\section{Measurement of browning value}

Apricot samples were first rehydrated in distilled water, and then rehydration water was clarified by centrifugation at $3200 \times g$ for $10 \mathrm{~min}$. The supernatant was diluted with an equal volume of $95 \%$ ethanol and centrifuged again at $3200 \times g$ for $10 \mathrm{~min}$. The browning value of the clear extracts was determined in quartz cell using a UV-visible spectrophotometer (Thermo Electron Corporation, Rosemount, MN, USA) at an absorbance of $420 \mathrm{~nm}$ (5). 


\section{Texture analysis}

A texture analyzer (model H5KS; Hounsfield Test Equipment, Redhill, UK) was used to measure the maximum tolerable force, which is related to the firmness of the dried apricots. The test parameters were set to a pretest speed of 0.1 $\mathrm{cm} / \mathrm{s}$, test speed of $0.2 \mathrm{~cm} / \mathrm{s}$, distance of $0.3 \mathrm{~cm}$ using cylindrical puncture flathead probe with a diameter of $0.2 \mathrm{~cm}$ (18).

\section{Microstructure analysis}

A scanning electron microscope (XL-30; Philips, Amsterdam, The Netherlands) was used to analyse the microstructural changes after OD and UOD pretreatments. SEM images of freeze-dried samples were obtained after coating of sample strips (thickness $0.1 \mathrm{~cm}$ ) with a very thin layer of gold under high vacuum (19).

\section{Microbiological analysis}

For all microbiological counts, $10 \mathrm{~g}$ sample were aseptically weighed and transferred into $90 \mathrm{~mL}$ Ringer's solution and homogenized. A dilution series of each samplewas prepared from $10^{-1}$ to $10^{-6}$. The total number of mesophilic aerobic microorganisms was estimated with plate count agar (PCA; Merck KGaA, Darmstadt, Germany). Yeasts and moulds were cultivated and counted with yeast extract glucose chloramphenicol agar (YGC; Merck KGaA). The PCA plates were incubated at $35^{\circ} \mathrm{C}$ for two days, whereas YGC plates were incubated at $25^{\circ} \mathrm{C}$ for five days. The results of all counts were recorded as the mean value of three measurements (2).

\section{Experimental design and statistical analysis}

In this study, a set of $3 \times 2 \times 3$ factorial experiments in a completely randomized way with three replicates were applied. Two ultrasound frequency levels ( 25 and $35 \mathrm{kHz}$ ), two immersion durations ( 30 and $45 \mathrm{~min}$ ), and three edible coatings (pectin with citric acid, pectin with ascorbic acid, and only pectin) were used. Physical properties including shrinkage, apparent and bulk densities, texture, microstructure, water activity, microbial load, and browning value were studied. The data obtained from experiments were analysed using Design-Expert software, v. 6.0.1 (20). To evaluate the difference between mean values of responses, Duncan's multiple range test was performed, and significant differences were defined at $p<0.05$. The Pearson correlation test was also used to determine any correlations among the responses.

\section{RESULTS AND DISCUSSION}

\section{Hot air drying curves}

The variation in moisture mass fraction of apricot cubes during hot air drying is shown in Fig. 1. The moisture content of hot air-dried OD-pretreated fresh apricots decreased from 4.0 to an average of $3.4 \mathrm{~kg} / \mathrm{kg}$. UOD treatment at $25 \mathrm{kHz}$ and both temperatures reduced the moisture mass fraction to 2.8 $\mathrm{kg} / \mathrm{kg}$, while the same treatment at $35 \mathrm{kHz}$ for 45 min caused the highest moisture decrease on dry matter basis $(2.3 \mathrm{~kg} /$ $\mathrm{kg}$ ). Control sample required a drying time of $9 \mathrm{~h}$ to reach a constant moisture of $0.2 \mathrm{~kg} / \mathrm{kg}$, while it took 8 and $7 \mathrm{~h}$ for the samples treated by OD for 35 and $45 \mathrm{~min}$, respectively. Drying time was $6 \mathrm{~h}$ for samples treated by UOD at $25 \mathrm{kHz}$ and 5 $\mathrm{h}$ at $35 \mathrm{kHz}$ at both temperatures. The higher rate of moisture loss of UOD-treated samples was due to the effect of power ultrasound in the formation of fractures and microchannels in the apricot tissue, which enhances drying rate and decreases drying time (7).

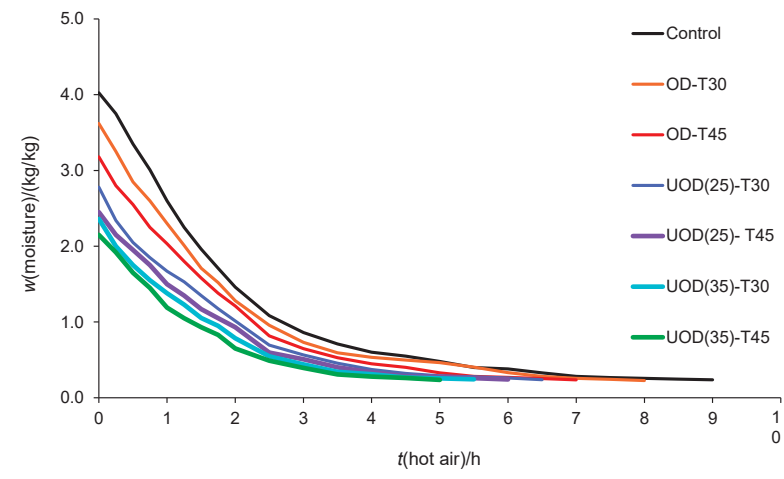

Fig. 1. Drying curves of apricot samples treated by osmotic dehydration (OD) for 30 (OD-T30) and $45 \mathrm{~min}$ (OD-T45), and ultrasond-assisted osmotic dehydration (UOD) at frequencies of $25(\mathrm{UOD}(25))$ and 35 $\mathrm{kHz}(\mathrm{UOD}(35))$ for 30 and $45 \mathrm{~min}$

\section{Browning value}

Fig. 2 represents the effect of OD, UOD and the use of different pectin-based coatings on the browning values of hot air-dried apricots. Application of pectin and pectin with citric acid coatings after the OD treatment reduced browning values in the hot air-dried samples. This can be explained by the effect of OD treatment on the inactivation of polyphenol oxidase enzyme (21) and the effect of active coatings in the inhibition of oxidation during hot air drying. We specifically show that pectin with citric acid coating has an effective role on browning inhibition in the OD-treated samples. Moreover, no significant differences ( $p>0.05$ ) were observed between the browning value of the OD-treated samples coated with either pectin or pectin with acetic acid. Browning values of the UOD-treated samples were higher than of the OD-treated samples. This may be attributed to the effect of power ultrasound in the breakdown of cell walls leading to possible exposure of amino acids and sugars that can participate in the Maillard reaction during drying. For this reason, increasing ultrasound frequency from 25 to $35 \mathrm{kHz}$ increased the browning value the UOD-treated samples. Moreover, UOD-treated samples coated with pectin and ascorbic acid showed higher browning values than samples coated with pectin and citric acid and pectin alone. Oxidation of L-ascorbic acid to L-dehydroascorbic acid and its participation in the Maillard reaction during drying can play a role here (22). 


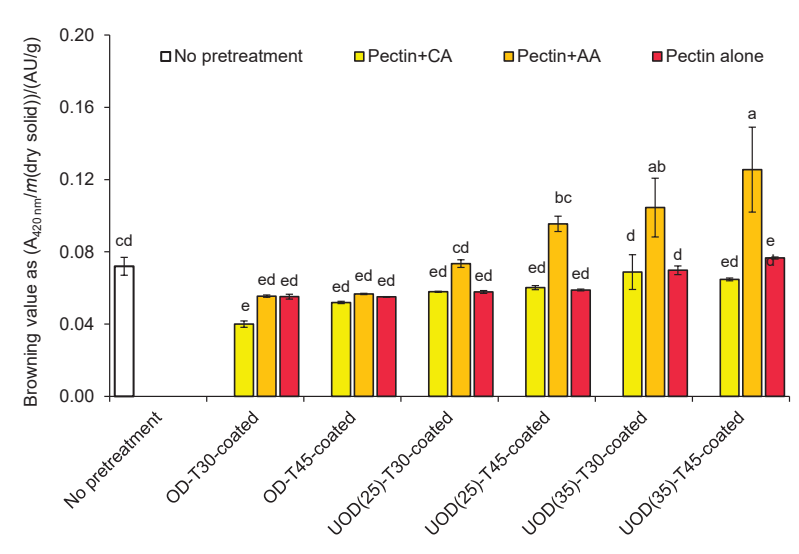

Fig. 2. Effect of different osmotic treatments (OD for 30 and $45 \mathrm{~min}$, UOD at 25 and $35 \mathrm{kHz}$ for 30 and $45 \mathrm{~min}$ ), and the application of pectin, pectin with citric acid (CA), and pectin with acetic acid (AA) coatings on browning values of hot air-dried apricots. Data are mean value of triplicate measurements. Error bars indicate S.D. values. Different letters correspond to significant $(p<0.05)$ differences between mean values. $\mathrm{OD}=0$ smotic dehydration, $\mathrm{UOD}=$ ultrasound-assisted osmotic dehydration

Fig. S1 shows the browning behaviour of OD- and UOD-treated samples coated with different coatings compared to control. OD-treated samples for 30 or 45 min showed similar browning effect. Likewise, OD samples coated with either pectin or pectin with ascorbic acid had comparable browning behaviour. However, samples treated for $45 \mathrm{~min}$ and coated with pectin and citric acid preserved their colour better. Also, UOD samples treated at $35 \mathrm{kHz}$ for 30 or $45 \mathrm{~min}$ and coated with pectin and ascorbic acid showed the highest browning effect. The lowest browning effect was observed in the UOD-treated samples with pectin and citric acid coating treated for $30 \mathrm{~min}$. These observations confirm the results presented in Fig. 2 .

\section{Firmness}

Fig. 3 shows firmness results, expressed as $F_{\max }$ values, of dried apricot samples treated with OD, UOD and coating (pectin, pectin with citric acid, and pectin with ascorbic acid). OD-treated and coated samples had higher firmness values than control. The results showed that the composition of active coatings significantly $(\mathrm{p}<0.05)$ affected $F_{\max }$ values. There was no significant $(\mathrm{p}<0.05)$ difference between the $F_{\max }$ of control and the OD-coated sample coated with pectin only. However, pectin with citric acid or pectin with acetic acid coatings gave higher $F_{\max }$ values than pectin only and control samples. This is possibly due to the acidic conditions in pectin coatings containing citric or acetic acid, which influenced the firmness values of these samples. Ben-Shalom et al. (23) studied the effect of acidification following blanching on the firmness of the carrot tissue. Blanching the carrot tissue at $\mathrm{pH}=6.2$ caused a significant reduction (about $70 \%$ ) in the firmness of the carrot tissue. For comparison, acidifying and blanching the tissue at $\mathrm{pH}=4.4$ increased (about $50 \%$ ) the firmness. Our results also show that OD-treated samples coated with pectin and citric

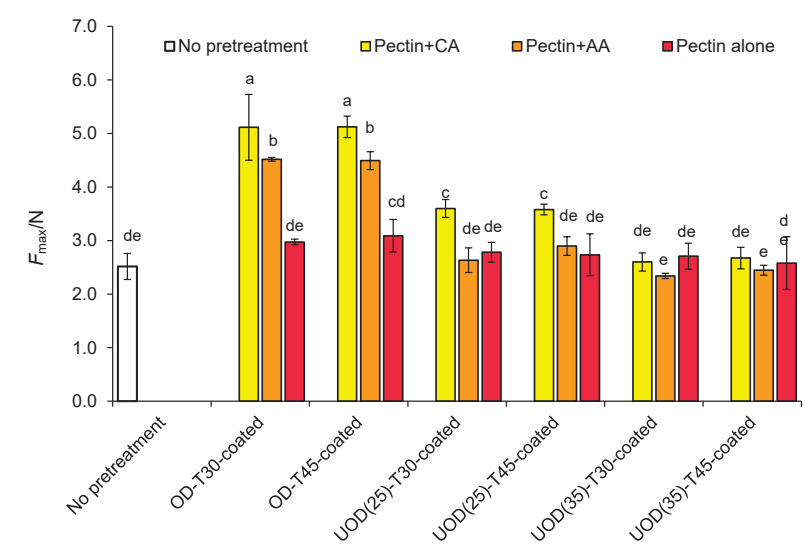

Fig. 3. Effect of different osmotic treatments (OD for 30 and 45 min, UOD at 25 and $35 \mathrm{kHz}$ for 30 and $45 \mathrm{~min}$ ), and the application of pectin, pectin with citric acid (CA), and pectin with ascorbic acid (AA) coatings on maximum force $\left(F_{\max }\right)$ of hot air-dried apricots. Data are mean of triplicate measurements. Error bars indicate S.D. values. Different letters represent significant $(p<0.05)$ differences between mean values. $\mathrm{OD}=$ osmotic dehydration, $\mathrm{UOD}=$ ultrasound-assisted osmotic dehydration

acid had significantly $(p<0.05)$ higher firmness values than that of pectin with acetic acid coating. OD treatment combined with power ultrasound (UOD) led to the firmness decline in these samples. There are two explanations here: (i) fractures and microchannels formed by power ultrasound cavitation effect in the apricot tissue caused a decrease of maximum force. These structural changes are seen well in SEM images (Fig. 4). Increase of ultrasound frequency from 25 to $35 \mathrm{kHz}$ led to a significant $(p<0.05)$ decrease in $F_{\max }$ values of UOD-treated samples. As seen in Fig. 4, larger cavities and fractures were formed in UOD samples treated at $35 \mathrm{kHz}$. Shamaei et al. (18) also reported a decrease of $F_{\max }$ values in air-dried samples by increasing the ultrasound frequency from 35 to $130 \mathrm{kHz}$ in the UOD pretreatment of cranberries; and (ii) UOD pretreatment of apricot in sorbitol solutions at $55^{\circ} \mathrm{C}$ resulted in more destruction of pectin inside apricot tissue, which causes softer texture of these samples. Xu et al. (24) reported that the simultaneous application of heat $\left(60^{\circ} \mathrm{C}\right)$ and power ultrasound on grapefruit skin facilitated the extraction of pectin and caused more destruction and depolymerization of pectin molecules. Liu and Zhang (25) also reported that application of power ultrasound on citrus pectin decreased the molecular mass of the pectin immediately after the pretreatment with ultrasound waves.

\section{Microstructural analysis}

SEM images of dried apricots are shown in Fig. 4. The image of dried apricot without pretreatment (control) showed destruction of the cell wall and tissue structure collapse. This observation is similar to the reported microstructure of rabbiteye blueberries dried without any pretreatment (26). SEM images of OD samples showed swollen inner tissue compared to that of control. Sponge-like tissue formed by cavities, fractures and microchannels were observed in the SEM images of 


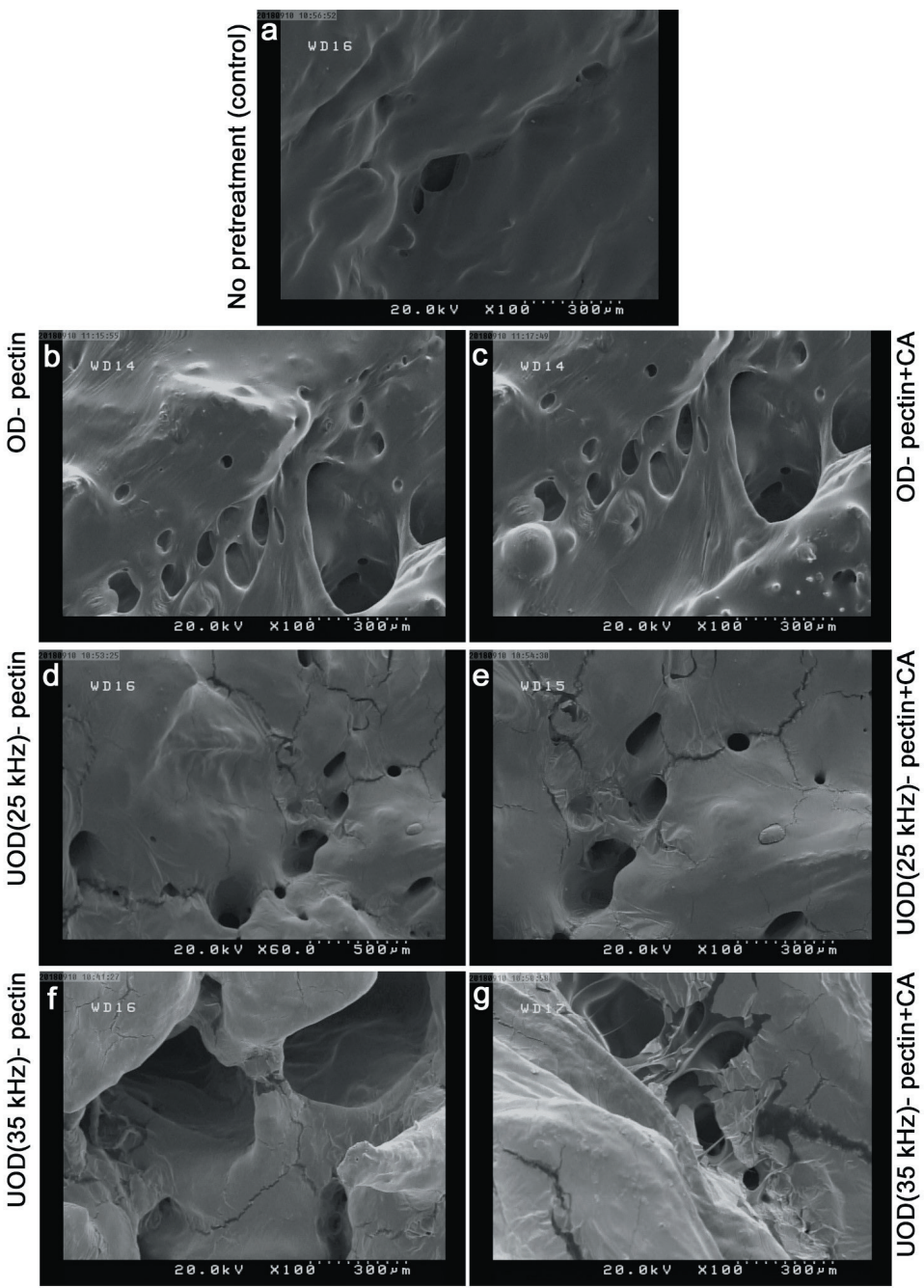

Fig. 4. Scanning electron microscopy (SEM) images of: a) control, OD-treated samples and coated with: b) pectin, c) pectin and citric acid, UOD-treated samples at $25 \mathrm{kHz}$ and coated with: d) pectin, e) pectin and citric acid, and UOD-treated samples at 35 $\mathrm{kHz}$ and coated with: f) pectin, g) pectin and citric acid. OD=osmotic dehydration, $\mathrm{UOD}=$ ultrasound-assisted osmotic dehydration

UOD-pretreated samples. Fernandes et al. (27) found that using ultrasound before drying of pineapple caused more destruction to cellular structure and created microchannels in the internal tissue. Garcia-Noguera et al. (19) reported that the observed changes in the texture of strawberry after application of UOD were due to the cavitation and the effects of induced osmotic pressure generated by ultrasound waves. Stojanovic and Silva (26) reported an extensive collapse in the external surface and cavities, which were distributed uniformly in the internal tissue of the berries pretreated by UOD. As observable in the SEM images in Fig. 4, increasing ultrasound frequency from 25 to $35 \mathrm{kHz}$ created large cavities in the internal tissue of apricot, which were not uniformly distributed. More destruction of inner tissue concurrent with the formation of more microchannels and large cavities have been reported by Shamaei et al. (18) when the frequency of ultrasound increased from 35 to $130 \mathrm{kHz}$ during UOD retreatment of cranberry. The obtained SEM images showed that pectin coatings with different composition did not affect the microstructure of both OD- and UOD-pretreated apricot samples. Garcia et al. (10) used TEM imaging to study the microstructure of coated and noncoated dried papaya and reported that the coating itself did not protect the tissue structure from changes during drying.

\section{Measurement of rehydration capacity}

Fig. 5 shows rehydration capacity of OD- and UOD-pretreated samples coated by pectin, pectin with citric and pectin with ascorbic acid coatings. OD-pretreated and coated samples had slightly higher rehydration capacity than control, although this difference is not significant ( $p>0.05)$. Higher rehydration capacity can be attributed to open internal tissue structure of the OD samples, also observable in SEM images (Fig. 4). Erba et al. (28) showed that the use of sugar alcohols such as sorbitol as the osmotic solution in the pretreatment of fruits could lead to products with good rehydration 


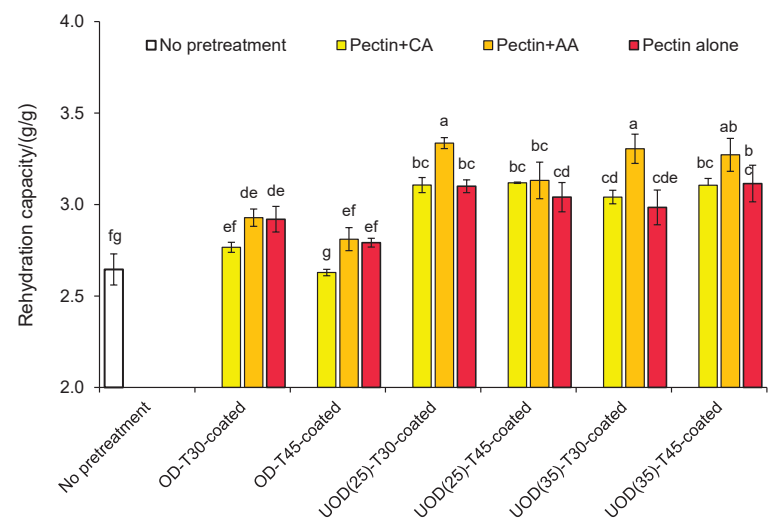

Fig. 5. Effect of different osmotic treatments (OD for 30 and 45 min, UOD at 25 and $35 \mathrm{kHz}$ for 30 and $45 \mathrm{~min}$ ), and the application of pectin, pectin with citric acid (CA), and pectin with ascorbic acid (AA) coatings on rehydration capacity of hot air-dried apricots. Data are mean value of triplicate measurements. Error bars indicate S.D. values. Different letters correspond to significant $(p<0.05)$ differences between mean values. $O D=0$ osmotic dehydration, $U O D=u l t r a-$ sound-assisted osmotic dehydration

properties, with possible application in bakery products and ice creams. Application of power ultrasound produced dried apricots with significantly $(p<0.05)$ higher rehydration capacity than of OD-treated and control samples. This can be explained by the formation of fractures, cavities and microchannel in the apricot tissue during UOD pretreatment (Fig. 4). Increasing ultrasound frequency from 25 to $35 \mathrm{kHz}$ had no significant ( $p>0.05$ ) effect on the rehydration capacity of UOD-pretreated samples. We also show that the coating of the pretreated apricots by different pectin coatings affected the rehydration capacity of the samples. The rehydration capacity of both treated samples coated with pectin and citric acid was significantly $(p<0.05)$ lower than that of coated with pectin and ascorbic acid. These findings are in agreement with those reported by Doymaz (29).

Table 1 compares the apparent and bulk densities, and shrinkage values of control sample with those of OD- and UOD-pretreated apricots with different coatings. Control had the lowest apparent and bulk densities, and the highest shrinkage compared to OD- and UOD-pretreated samples. Application of OD before drying with hot air resulted in a significant $(p<0.05)$ increase in bulk and apparent densities. These results are consistent with earlier studies that reported the effect of OD on the increase of the bulk density of hot air-dried apples $(30,31)$. Udomkun et al. (32) reported that osmotic treatment of papaya slices before freeze-drying increased apparent density and solid density of the samples. Shrinkage decreased in OD-pretreated and coated samples compared to control. This is attributed to the filling of spaces between the cells by soluble solids of the osmotic solution and reducing any structure collapse in apricot tissue (33). SEM images in Fig. 4 display extensively swollen internal tissue in osmotically pretreated samples that can prevent shrinkage during hot air drying. Reppa et al. (34) found that osmotic pretreatment of apple slices decreased the shrinkage of dried samples, and there is a direct relationship between the reduction of shrinkage and mass transfer of soluble solids from the osmotic solution to fruit tissue. Table 1 shows that the UOD pretreatment significantly $(\mathrm{p}<0.05)$ reduced shrinkage and

Table 1. Variation of bulk $\left(\rho_{\mathrm{b}}\right)$ and apparent $\left(\rho_{\mathrm{a}}\right)$ densities, and shrinkage $\left(S_{\mathrm{b}}\right)$ in non-treated (control) and air-dried apricots by different pretreatments: osmotic dehydration (OD) for 30 and $45 \mathrm{~min}$, ultrasound-assisted osmotic dehydration (UOD) at 25 and $35 \mathrm{kHz}$ for 30 and $45 \mathrm{~min}$, and application of coatings consisting of pectin only (P), pectin with citric acid (CA), and pectin with ascorbic acid (AA)

\begin{tabular}{|c|c|c|c|}
\hline Pretreatment & $\rho_{\mathrm{b}} /\left(\mathrm{g} / \mathrm{cm}^{3}\right)$ & $\rho_{\mathrm{a}} /\left(\mathrm{g} / \mathrm{cm}^{3}\right)$ & $S_{b} / \%$ \\
\hline Dried, non-treated (control) & $(1.358 \pm 0.000)^{g}$ & $(1.260 \pm 0.000)^{g}$ & $(84.5 \pm 0.9)^{f}$ \\
\hline OD-T30-coated $(P+C A)$ & $(1.368 \pm 0.002)^{f}$ & $(1.266 \pm 0.002)^{\mathrm{efg}}$ & $(83.2 \pm 0.1)^{\text {ef }}$ \\
\hline OD-T30-coated (P+AA) & $(1.366 \pm 0.000)^{f}$ & $(1.262 \pm 0.004)^{\mathrm{fg}}$ & $(83.1 \pm 0.2)^{\mathrm{ef}}$ \\
\hline OD-T30-coated (P) & $(1.366 \pm 0.000)^{f}$ & $(1.259 \pm 0.003)^{\mathrm{g}}$ & $(83.0 \pm 0.5)^{\text {ef }}$ \\
\hline OD-T45-coated $(\mathrm{P}+\mathrm{CA})$ & $(1.367 \pm 0.000)^{f}$ & $(1.268 \pm 0.002)^{\text {defg }}$ & $(80.4 \pm 0.7)^{\mathrm{abcd}}$ \\
\hline OD-T45-coated $(P+A A)$ & $(1.367 \pm 0.000)^{f}$ & $(1.268 \pm 0.000)^{\text {defg }}$ & $(81.1 \pm 0.3)^{\text {bcde }}$ \\
\hline OD-T45-coated (P) & $(1.367 \pm 0.000)^{f}$ & $(1.268 \pm 0.001)^{\text {defg }}$ & $(81.3 \pm 1.0)^{\text {cde }}$ \\
\hline UOD(25)-T30-coated (P+CA) & $(1.405 \pm 0.000)^{d}$ & $(1.279 \pm 0.002)^{\mathrm{bcdef}}$ & $(82.4 \pm 1.6)^{\mathrm{de}}$ \\
\hline UOD(25)-T30-coated (P+AA) & $(1.399 \pm 0.020)^{\mathrm{e}}$ & $(1.273 \pm 0.002)^{\text {cdefg }}$ & $(81.5 \pm 0.7)^{\text {cde }}$ \\
\hline UOD(25)-T30-coated (P) & $(1.403 \pm 0.000)^{\mathrm{cd}}$ & $(1.279 \pm 0.003)^{\mathrm{bcdef}}$ & $(81.8 \pm 0.5)^{\text {cde }}$ \\
\hline UOD(25)-T45-coated (P+CA) & $(1.404 \pm 0.002)^{\mathrm{bcd}}$ & $(1.283 \pm 0.001)^{\mathrm{bcde}}$ & $(79.9 \pm 1.9)^{\mathrm{abc}}$ \\
\hline UOD(25)-T45-coated (P+AA) & $(1.402 \pm 0.002)^{\mathrm{d}}$ & $(1.283 \pm 0.000)^{\mathrm{bcde}}$ & $(81.2 \pm 0.10)^{\text {cde }}$ \\
\hline UOD(25)-T45-coated (P) & $(1.405 \pm 0.000)^{\mathrm{abcd}}$ & $(1.286 \pm 0.007)^{\mathrm{abc}}$ & $(81.0 \pm 0.3)^{\text {bcde }}$ \\
\hline UOD(35)-T30-coated (P+CA) & $(1.404 \pm 0.001)^{\mathrm{bcd}}$ & $(1.283 \pm 0.004)^{\mathrm{bcde}}$ & $(81.6 \pm 0.5)^{\text {cde }}$ \\
\hline UOD(35)-T30-coated $(P+A A)$ & $(1.405 \pm 0.002)^{\mathrm{abcd}}$ & $(1.284 \pm 0.003)^{\mathrm{abcd}}$ & $(80.6 \pm 0.8)^{\mathrm{abcd}}$ \\
\hline UOD(35)-T30-coated (P) & $(1.405 \pm 0.002)^{\mathrm{abcd}}$ & $(1.284 \pm 0.009)^{\mathrm{bcd}}$ & $(80.6 \pm 0.8)^{\mathrm{abcd}}$ \\
\hline UOD(35)-T45-coated (P+CA) & $(1.407 \pm 0.000)^{\mathrm{a}}$ & $(1.301 \pm 0.013)^{\mathrm{a}}$ & $(79.0 \pm 1.0)^{\mathrm{ab}}$ \\
\hline UOD(35)-T45-coated (P+AA) & $(1.407 \pm 0.000)^{\mathrm{ab}}$ & $(1.296 \pm 0.006)^{\mathrm{ab}}$ & $(79.0 \pm 1.3)^{\mathrm{ab}}$ \\
\hline UOD(35)-T45-coated (P) & $(1.406 \pm 0.000)^{\mathrm{abc}}$ & $(1.291 \pm 0.006)^{\mathrm{ab}}$ & $(78.7 \pm 1.2)^{\mathrm{a}}$ \\
\hline
\end{tabular}

Data are mean value of triplicate measurements \pm standard deviation. Different letters in each column represent significant $(p<0.05)$ differences between mean values 
increased apparent and bulk densities of dried apricots. The created cavities and microchannels in the tissue of UOD-pretreated samples (Fig. 4) facilitate penetration of soluble solids from osmotic solution into the tissue during UOD pretreatment. Moreover, these structural changes enhance drying speed, and therefore, decrease the shrinkage of UOD-pretreated samples during hot air drying. This effect was even more enhanced when ultrasound frequency increased from 25 to $35 \mathrm{kHz}$. Stojanovic and Silva (26) reported an increase in the bulk density of UOD-pretreated rabbiteye blueberries. UOD-pretreated samples treated at $35 \mathrm{kHz}$ for $45 \mathrm{~min}$ had the lowest shrinkage and the highest apparent density values. Samples with higher bulk density had higher rehydration capacity and lower shrinkage values.

Table 2 shows the average values of water and soluble solid content of the fresh and pretreated dried apricot samples. The initial water mass fraction decreased from 82 to 21-27 $\mathrm{g} / 100 \mathrm{~g}$ fruit in pretreated dried apricots. Therefore, the soluble solid content increased from 18 to around 79-73 g/100 $\mathrm{g}$ fruit liquid phase in these samples. The water activity was 0.929 in fresh samples, which decreased to 0.628 in non-treated dried apricots. Sugar content increase due to osmotic dehydration (with or without ultrasound) affected the water activity in the pretreated dried apricots. Water activity was within the range of $0.547-0.560$ in OD-pretreated and coated samples. The formed cavities and microchannels in the
UOD-pretreated apricot tissue (Fig. 4) increased sugar content and accelerated water loss during UOD pretreatment. Table 2 shows that with the increase of the mass fraction of soluble solids from $0.641-0.644 \mathrm{~g} / \mathrm{g}$ in the OD-pretreated samples to $0.672-0.724 \mathrm{~g} / \mathrm{g}$ in the UOD-pretreated ones sugar content in the UOD-pretreated samples increased. Increase in sugar gain significantly affected water activity in these samples as it was lower in the UOD-pretreated samples than in the OD-pretreated ones. Kowalski et al. (35) reported that ultrasound-assisted osmotic dehydration in combination with intermittent-convective drying of cherry caused lower water activity. Also, an increase of ultrasound frequency from 25 to $35 \mathrm{kHz}$ significantly $(p<0.05)$ increased the mass fraction of soluble solids in these samples and led to significant $(p<0.05)$ reduction in water activity of the UOD-treated apricots. The water activity of the UOD-pretreated and coated apricots was $0.546-0.522$. The samples treated at $35 \mathrm{kHz}$ had the lowest water activity. Shamaei et al. (18) indicated that increasing the ultrasound frequency from 35 to $130 \mathrm{kHz}$ in ultrasound-assisted osmotic dehydration of cranberry decreased the water activity of the dried cranberries. Statistical analysis indicated that coatings and their compositions did not have any significant ( $p>0.05$ ) effects on the water activity of dried apricots. Immersion duration in both OD- and UOD-pretreated samples did not change the water activity of dried samples significantly.

Table 2. Variation of the mass fraction of soluble solids $\left(X_{s}\right)$, mass fraction of water $\left(X_{w}\right)$ and water activity $\left(a_{\mathrm{w}}\right)$ in non-treated (control) and air-dried apricots by different pretreatments: osmotic dehydration (OD) for 30 and $45 \mathrm{~min}$, ultrasound-assisted osmotic dehydration (UOD) at 25 and $35 \mathrm{kHz}$ for 30 and $45 \mathrm{~min}$, and application of coatings consisting of pectin only $(P)$, pectin with citric acid (CA), and pectin with ascorbic $\operatorname{acid}(\mathrm{AA})$

\begin{tabular}{lccc}
\multicolumn{1}{c}{ Pretreatment } & $X_{\mathrm{s}} /(\mathrm{g} / \mathrm{g})$ & $X_{\mathrm{w}} /(\mathrm{g} / \mathrm{g})$ & $a_{\mathrm{w}}$ \\
Fresh apricot & $(0.186 \pm 0.002)^{\mathrm{k}}$ & $(0.824 \pm 0.000)^{\mathrm{a}}$ & $(0.929 \pm 0.003)^{\mathrm{e}}$ \\
Dried (no pretreatment) & $(0.622 \pm 0.000)^{\mathrm{i}}$ & $(0.294 \pm 0.000)^{\mathrm{b}}$ & $(0.628 \pm 0.004)^{\mathrm{d}}$ \\
OD-T30-coated (P+CA) & $(0.641 \pm 0.001)^{\mathrm{h}}$ & $(0.275 \pm 0.002)^{\mathrm{c}}$ & $(0.548 \pm 0.000)^{\mathrm{b}}$ \\
OD-T30-coated (P+AA) & $(0.642 \pm 0.001)^{\mathrm{h}}$ & $(0.278 \pm 0.000)^{\mathrm{c}}$ & $(0.561 \pm 0.003)^{\mathrm{c}}$ \\
OD-T30-coated (P) & $(0.642 \pm 0.00)^{\mathrm{h}}$ & $(0.278 \pm 0.000)^{\mathrm{c}}$ & $(0.549 \pm 0.002)^{\mathrm{b}}$ \\
OD-T45-coated (P+CA) & $(0.643 \pm 0.000)^{\mathrm{h}}$ & $(0.277 \pm 0.000)^{\mathrm{c}}$ & $(0.547 \pm 0.001)^{\mathrm{b}}$ \\
OD-T45-coated (P+AA) & $(0.644 \pm 0.001)^{\mathrm{h}}$ & $(0.276 \pm 0.000)^{\mathrm{c}}$ & $(0.548 \pm 0.000)^{\mathrm{b}}$ \\
OD-T45-coated (P) & $(0.643 \pm 0.000)^{\mathrm{h}}$ & $(0.277 \pm 0.000)^{\mathrm{c}}$ & $(0.549 \pm 0.005)^{\mathrm{b}}$ \\
UOD(25)-T30-coated (P+CA) & $(0.672 \pm 0.007)^{\mathrm{g}}$ & $(0.227 \pm 0.007)^{\mathrm{e}}$ & $(0.531 \pm 0.001)^{\mathrm{a}}$ \\
UOD(25)-T30-coated (P+AA) & $(0.681 \pm 0.003)^{\mathrm{f}}$ & $(0.232 \pm 0.003)^{\mathrm{d}}$ & $(0.546 \pm 0.001)^{\mathrm{b}}$ \\
UOD(25)-T30-coated (P) & $(0.682 \pm 0.002)^{\mathrm{f}}$ & $(0.226 \pm 0.002)^{\mathrm{ef}}$ & $(0.541 \pm 0.002)^{\mathrm{b}}$ \\
UOD(25)-T45-coated (P+CA) & $(0.703 \pm 0.006)^{\mathrm{de}}$ & $(0.225 \pm 0.006)^{\mathrm{ef}}$ & $(0.540 \pm 0.002)^{\mathrm{b}}$ \\
UOD(25)-T45-coated (P+AA) & $(0.698 \pm 0.007)^{\mathrm{e}}$ & $(0.227 \pm 0.007)^{\mathrm{e}}$ & $(0.542 \pm 0.003)^{\mathrm{b}}$ \\
UOD(25)-T45-coated (P) & $(0.695 \pm 0.009)^{\mathrm{e}}$ & $(0.223 \pm 0.010)^{\mathrm{efg}}$ & $(0.542 \pm 0.005)^{\mathrm{b}}$ \\
UOD(35)-T30-coated (P+CA) & $(0.716 \pm 0.007)^{\mathrm{abc}}$ & $(0.225 \pm 0.007)^{\mathrm{efg}}$ & $(0.527 \pm 0.002)^{\mathrm{a}}$ \\
UOD(35)-T30-coated (P+AA) & $(0.713 \pm 0.010)^{\mathrm{bc}}$ & $(0.223 \pm 0.010)^{\mathrm{efg}}$ & $(0.522 \pm 0.004)^{\mathrm{a}}$ \\
UOD(35)-T30-coated (P) & $(0.708 \pm 0.005)^{\mathrm{cd}}$ & $(0.223 \pm 0.005)^{\mathrm{efg}}$ & $(0.526 \pm 0.008)^{\mathrm{a}}$ \\
UOD(35)-T45-coated (P+CA) & $(0.724 \pm 0.010)^{\mathrm{a}}$ & $(0.220 \pm 0.000)^{\mathrm{h}}$ & $(0.531 \pm 0.001)^{\mathrm{a}}$ \\
UOD(35)-T45-coated (P+AA) & $(0.720 \pm 0.002)^{\mathrm{ab}}$ & $(0.220 \pm 0.002)^{\mathrm{gh}}$ & $(0.529 \pm 0.009)^{\mathrm{a}}$ \\
UOD(35)-T45-coated (P) & $(0.722 \pm 0.000)^{\mathrm{a}}$ & $(0.222 \pm 0.000)^{\mathrm{fgh}}$ & $(0.531 \pm 0.002)^{\mathrm{a}}$
\end{tabular}

Data are mean value of triplicate measurements \pm standard deviation. Different letters in each column represent significant $(p<0.05)$ differences between mean values 
Table 3. Microbial load of non-treated (control) and air-dried apricots by different pretreatments: osmotic dehydration (OD) for 30 and 45 min, ultrasound-assisted osmotic dehydration (UOD) at 25 and $35 \mathrm{kHz}$ for 30 and $45 \mathrm{~min}$, and application of coatings consisting of pectin only $(P)$, pectin with citric acid (CA), and pectin with ascorbic acid (AA)

$\begin{array}{lcc}\text { Pretreatment } & \begin{array}{c}\text { N(total } \\ \text { mesophyllic } \\ \text { aerobic count)/ } \\ \text { (CFU/g) }\end{array} & \begin{array}{c}N(\text { total } \\ \text { yeast and } \\ \text { mould)/ } \\ (\text { CFU/g) }\end{array} \\ \text { Dried (no pretreatment) } & (115 \pm 7)^{\mathrm{a}} & (40 \pm 7)^{\mathrm{a}} \\ \text { OD-T30-coated (P+CA) } & (65 \pm 7)^{\mathrm{cde}} & (25 \pm 0)^{\mathrm{cd}} \\ \text { OD-T30-coated (P+AA) } & (75 \pm 7)^{\mathrm{bc}} & (30 \pm 7)^{\mathrm{bc}} \\ \text { OD-T30-coated (P) } & (85 \pm 7)^{\mathrm{b}} & (35 \pm 7)^{\mathrm{ab}} \\ \text { OD-T45-coated (P+CA) } & (60 \pm 1)^{\mathrm{def}} & (20 \pm 0)^{\mathrm{de}} \\ \text { OD-T45-coated (P+AA) } & (70 \pm 14)^{\mathrm{cd}} & (20 \pm 14)^{\mathrm{def}} \\ \text { OD-T45-coated (P) } & (75 \pm 7)^{\mathrm{bc}} & (20 \pm 7)^{\mathrm{de}} \\ \text { UOD(25)-T30-coated (P+CA) } & (50 \pm 0)^{\mathrm{fgh}} & (10 \pm 0)^{\mathrm{h}} \\ \text { UOD(25)-T30-coated (P+AA) } & (55 \pm 7)^{\mathrm{efg}} & (15 \pm 0)^{\mathrm{fg}} \\ \text { UOD(25)-T30-coated (P) } & (60 \pm 0)^{\mathrm{def}} & (15 \pm 0)^{\mathrm{fg}} \\ \text { UOD(25)-T45-coated (P+CA) } & (45 \pm 7)^{\mathrm{ghi}} & (10 \pm 7)^{\mathrm{hi}} \\ \text { UOD(25)-T45-coated (P+AA) } & (50 \pm 0)^{\mathrm{fgh}} & (10 \pm 0)^{\mathrm{h}} \\ \text { UOD(25)-T45-coated (P) } & (55 \pm 7)^{\mathrm{efg}} & (15 \pm 7)^{\mathrm{fgh}} \\ \text { UOD(35)-T30-coated (P+CA) } & (40 \pm 0)^{\mathrm{hi}} & (0 \pm 0)^{\mathrm{j}} \\ \text { UOD(35)-T30-coated (P+AA) } & (45 \pm 7)^{\mathrm{ghi}} & (0 \pm 0)^{\mathrm{j}} \\ \text { UOD(35)-T30-coated (P) } & (50 \pm 0)^{\mathrm{fgh}} & (5.0 \pm 3.5)^{\mathrm{i}} \\ \text { UOD(35)-T45-coated (P+CA) } & (35 \pm 7)^{\mathrm{i}} & (0 \pm 0)^{\mathrm{j}} \\ \text { UOD(35)-T45-coated (P+AA) } & (40 \pm 0)^{\mathrm{hi}} & (0 \pm 0)^{\mathrm{j}} \\ \text { UOD(35)-T45-coated (P) } & (50 \pm 0)^{\mathrm{fgh}} & (0 \pm 0)^{\mathrm{j}}\end{array}$

Data are mean value of duplicate measurements \pm standard deviation. Different letters in each column represent significant $(p<0.05)$ differences between mean values

Table 3 demonstrates the microbial load of nontreated and OD/UOD/coating-treated air-dried apricots. The total mesophilic aerobic count and total yeast and mould count in nontreated air-dried apricots was 115 and 40 CFU/g, respectively. Table 3 shows that the total mesophilic aerobic count and yeast and mould counts reduced significantly $(p<0.05)$ in the OD-pretreated and coated dried apricots. This reduction can be attributed to a reduced water activity of these samples (Table 2). It is known that at the water activity less than 0.6 , the activity of bacteria, moulds and yeasts is very low $(8,35)$. Water activity in control sample was 0.629 , which was reduced to $0.547-0.560$ in the OD-pretreated and coated samples. Indeed, this reduction provided a substantial decrease in the microbial load of these samples. Also, the evaluation of microbial load in the UOD-pretreated and coated dried apricots indicated that the UOD pretreatment had a positive effect on the microbial load reduction in these samples compared to the OD pretreatment. The total mesophilic aerobic count decreased by $0.29-0.52$ log cycles in the UOD-pretreated and coated dried samples compared to the control. Villalobos et al. (36) reported that UOD-pretreated figs had the lowest microbial load compared to traditionally dried samples. UOD-treated apricot samples at $35 \mathrm{kHz}$ for $45 \mathrm{~min}$ had the lowest total mesophilic aerobic count and total yeast and mould count. There was no significant $(p<0.05)$ difference between the microbial load of dried apricots treated with OD or UOD and coated with three different coatings.

\section{CONCLUSIONS}

The application of ultrasound-assisted osmotic dehydration (UOD) pretreatment in sorbitol solutions before hot air drying of apricots resulted in the improvement of physical properties such as shrinkage, apparent density, bulk density, rehydration capacity and texture of the dried apricots. When ultrasound frequency was increased from 25 to $35 \mathrm{kHz}$, firmness decreased, and rehydration capacity increased. While the UOD of apricot samples increased the browning value of the air-dried apricots, the osmotic dehydration (OD) resulted in better colour preservation. After increasing ultrasound frequency from 25 to $35 \mathrm{kHz}$, discoloration increased in the UOD-pretreated samples. Coating of both OD- and UOD-pretreated samples with pectin with citric acid increased firmness and decreased rehydration capacity. Application of UOD pretreatment led to water activity and microbial load reduction.

\section{CONFLICT OF INTEREST}

This research was conducted in the absence of any commercial or financial relationships that could be construed as a potential conflict of interest. The authors declare no conflict of interest.

\section{AUTHORS' CONTRIBUTION}

R. Sakooei-Vayghan performed sample synthesis, analysis and collected test data, and drafted the manuscript. S.H. Peighambardoust designed and supervised the research, interpreted the results and revised the manuscript critically. J. Hesari contributed in analysing and interpreting the results and discussions. M. Soltanzadeh assisted in interpreting the results, improving English grammar and fluency of the revised manuscript. D. Peressini assisted in analysing and interpreting the results in final format reading, and improved English grammar. All authors approved the final version of the manuscript and agreed to be accountable for all aspects of the work.

\section{SUPPLEMENTARY MATERIALS}

All supplementary materials are available at: www.ftb. com.hr.

\section{ORCID ID}

R. Sakooei-Vayghan (ㄱ https://orcid.org/0000-0002-0299-7831 S.H. Peighambardoust (1) https://orcid.org/0000-0002-8438-7315 J. Hesari (1) https://orcid.org/0000-0003-4684-4391 M. Soltanzadeh ํ https://orcid.org/0000-0002-5487-7102

D. Peressini @ 1 https://orcid.org/0000-0001-7848-9609

\section{REFERENCES}

1. Saracoglu S, Tuzen M, Soylak M. Evaluation of trace element contents of dried apricot samples from Turkey. J Hazard Mater. 2009;167(1-3):647-52.

https://doi.org/10.1016/j.jhazmat.2009.01.011 
2. Karabulut I, Topcu A, Duran A, Turan S, Ozturk B. Effect of hot air drying and sun drying on color values and $\beta$-carotene content of apricot (Prunus armenica L.). LWT - Food Sci Technol. 2007;40(5):753-8.

https://doi.org/10.1016/j.lwt.2006.05.001

3. Albanese D, Cinquanta L, Cuccurullo G, Di Matteo M. Effects of microwave and hot-air drying methods on colour, $\beta$-carotene and radical scavenging activity of apricots. Int J Food Sci Technol. 2013;48(6):1327-33.

https://doi.org/10.1111/ijfs.12095

4. Altındağ $M$, Türkyılmaz $M$, Özkan M. Changes in polyphenol profile of dried apricots containing $\mathrm{SO}_{2}$ at various concentrations during storage. J Sci Food Agric. 2018;98(7):2530-9. https://doi.org/10.1002/jsfa.8740

5. Hamzaoğlu F, Türkyilmaz M, Özkan M. Amino acid profile and content of dried apricots containing $\mathrm{SO}_{2}$ at different concentrations during storage. Qual Assur Saf Crop Foods. 2018;10(4):361-9. https://doi.org/10.3920/QAS2018.1284

6. Lemus-Mondaca R, Miranda M, Andres Grau A, Briones V, Villalobos R, Vega-Gálvez A. Effect of osmotic pretreatment on hot air drying kinetics and quality of Chilean papaya (Carica pubescens). Dry Technol. 2009;27(10):1105-15. https://doi.org/10.1080/07373930903221291

7. Çağlayan D, Barutçu Mazı I. Effects of ultrasound-assisted osmotic dehydration as a pretreatment and finish drying methods on the quality of pumpkin slices. J Food Process Preserv. 2018;42(9):e13679.

https://doi.org/10.1111/jfpp.13679

8. Bromberger Soquetta M, Schmaltz S, Wesz Righes F, Salvalaggio $R$, de Marsillac Terra L. Effects of pretreatment ultrasound bath and ultrasonic probe, in osmotic dehydration, in the kinetics of oven drying and the physicochemical properties of beet snacks. J Food Process Preserv. 2018;42(1):e13393.

https://doi.org/10.1111/jfpp.13393

9. Silva KS, Garcia CC, Amado LR, Mauro MA. Effects of edible coatings on convective drying and characteristics of the dried pineapple. Food Bioprocess Technol. 2015;8:1465-75. https://doi.org/10.1007/s11947-015-1495-y

10. Garcia CC, Caetano LC, de Souza Silva K, Mauro MA. Influence of edible coating on the drying and quality of papaya (Carica papaya). Food Bioprocess Technol. 2014;7:2828-39. https://doi.org/10.1007/s11947-014-1350-6

11. Ghasemzadeh R, Karbassi A, Ghoddousi HB. Application of edible coating for improvement of quality and shelf-life of raisins. World Appl Sci J. 2008;3(1):82-7.

12. Cheng XF, Zhang M, Adhikari B. The inactivation kinetics of polyphenol oxidase in mushroom (Agaricus bisporus) during thermal and thermosonic treatments. Ultrason Sonochem. 2013;20(2):674-9.

https://doi.org/10.1016/j.ultsonch.2012.09.012
13. Tortoe C. A review of osmodehydration for food industry. Afr J Food Sci. 2010;4(6):303-24.

https://doi.org/10.5897/AJFS.9000007

14. Fernandes FAN, Gallão MI, Rodrigues S. Effect of osmotic dehydration and ultrasound pre-treatment on cell structure: Melon dehydration. LWT - Food Sci Technol. 2008;41(4):604-10.

https://doi.org/10.1016/j.lwt.2007.05.007

15. Deng Y, Zhao Y. Effect of pulsed vacuum and ultrasound osmopretreatments on glass transition temperature, texture, microstructure and calcium penetration of dried apples (Fuji). LWT - Food Sci Technol. 2008;41(9):1575-85.

https://doi.org/10.1016/j.lwt.2007.10.018

16. AOAC Official Method 927.05-1927. Moisture in dried milk. Rockville, MD, USA: AOAC International; 2011.

17. Taiwo KA, Angersbach A, Knorr D. Rehydration studies on pretreated and osmotically dehydrated apple slices. J Food Sci. 2002;67(2):842-7.

https://doi.org/10.1111/j.1365-2621.2002.tb10687.x

18. Shamaei S, Emam-Djomeh Z, Moini S. Ultrasound-assisted osmotic dehydration of cranberries: Effect of finish drying methods and ultrasonic frequency on textural properties. J Texture Stud. 2012;43(2):133-41.

https://doi.org/10.1111/j.1745-4603.2011.00323.x

19. Garcia-Noguera J, Oliveira FIP, Gallão MI, Weller CL, Rodrigues S, Fernandes FAN. Ultrasound-assisted osmotic dehydration of strawberries: Effect of petreatment time and ultrasonic frequency. Dry Technol. 2010;28(2):294-303.

https://doi.org/10.1080/07373930903530402

20. Design-Expert, v. 6.0.1, Stat-Ease Inc., Minneapolis, MN, USA; 2017. Available from: www.statease.com/software/ design-expert.

21. Riva M, Campolongo S, Leva AA, Maestrelli A, Torreggiani D. Structure-property relationships in osmo-air-dehydrated apricot cubes. Food Res Int. 2005;38(5):533-42.

https://doi.org/10.1016/j.foodres.2004.10.018

22. Pischetsrieder M, Larisch B, Severin T. The Maillard reaction of ascorbic acid with amino acids and proteins - Identification of products. In: O'Brien J, Nursten HE, Crabbe MJC, Ames JM, editors. The Maillard reaction in foods and medicine. Series in Food Science, Technology and Nutrition. Cambridge, UK: Woodhead Publishing; 2005. pp. 107-12. https://doi.org/10.1533/9781845698447.2.107

23. Ben-Shalom N, Plat D, Levi A, Pinto R. Changes in molecular weight of water-soluble and EDTA-soluble pectin fractions from carrot after heat treatments. Food Chem. 1992;45(4):243-5.

https://doi.org/10.1016/0308-8146(92)90154-T

24. Xu Y, Zhang L, Bailina Y, Ge Z, Ding T, Ye X, Liu D. Effects of ultrasound and/or heating on the extraction of pectin from grapefruit peel. J Food Eng. 2014;126:72-81.

https://doi.org/10.1016/j.jfoodeng.2013.11.004 
25. Liu D, Zhang L. The influence of ultrasound on the structure, rheological properties, and degradation path of citrus pectin. J Acoust Soc Am. 2013;133(5):3595.

https://doi.org/10.1121/1.4806648

26. Stojanovic J, Silva JL. Influence of osmoconcentration, continuous high-frequency ultrasound and dehydration on properties and microstructure of rabbiteye blueberries. Dry Technol. 2006;24(2):165-71. https://doi.org/10.1080/07373930600558995

27. Fernandes FAN, Gallão MI, Rodrigues S. Effect of osmosis and ultrasound on pineapple cell tissue structure during dehydration. J Food Eng. 2009;90(2):186-90. https://doi.org/10.1016/j.jfoodeng.2008.06.021

28. Erba ML, Forni E, Colonello A, Giangiacomo R. Influence of sugar composition and air dehydration levels on the chemical-physical characteristics of osmodehydrofrozen fruit. Food Chem. 1994;50(1):69-73.

https://doi.org/10.1016/0308-8146(94)90095-7

29. Doymaz I. Effect of citric acid and blanching pre-treatments on drying and rehydration of Amasya red apples. Food Bioprod Process. 2010;88(2-3):124-32.

https://doi.org/10.1016/j.fbp.2009.09.003

30. Nieto AB, Salvatori DM, Castro MA, Alzamora SM. Structural changes in apple tissue during glucose and sucrose osmotic dehydration: Shrinkage, porosity, density and microscopic features. J Food Eng. 2004;61(2):269-78. https://doi.org/10.1016/S0260-8774(03)00108-0
31. Krokida MK, Maroulis ZB. Effect of drying method on shrinkage and porosity. Dry Technol. 1997;15(10):2441-58. https://doi.org/10.1080/07373939708917369

32. Udomkun $P$, Argyropoulos D, Nagle M, Mahayothee $B$, Oladeji $A E$, Müller J. Changes in microstructure and functional properties of papaya as affected by osmotic pre-treatment combined with freeze-drying. J Food Meas Charact. 2018;12:1028-37. https://doi.org/10.1007/s11694-018-9718-3

33. Yağcı S, Göğüş F. Response surface methodology for evaluation of physical and functional properties of extruded snack foods developed from food-by-products. J Food Eng. 2008;86(1):122-32. https://doi.org/10.1016/j.jfoodeng.2007.09.018

34. Reppa A, Mandala J, Kostaropoulos AE, Saravacos GD. Influence of solute temperature and concentration on the combined osmotic and air drying. Dry Technol. 1999;17(78):1449-58.

https://doi.org/10.1080/07373939908917627

35. Kowalski SJ, Szadzińska J, Pawłowski A. Ultrasonic-assisted osmotic dehydration of carrot followed by convective drying with continuous and intermittent heating. Dry Technol. 2015;33(13):1570-80.

https://doi.org/10.1080/07373937.2015.1012265

36. Villalobos MC, Serradilla MJ, Martín A, Ruíz-Moyano S, Casquete R, Hernández A, Córdoba MG. Use of efficient drying methods to improve the safety and quality of dried fig. J Food Process Preserv. 2019;43(1):e13853.

https://doi.org/10.1111/jfpp.13853 